\title{
Health Services Insights
}

\section{A Geographical Study of Health Services Utilization Among the Elderly in Hong Kong: From Spatial Variations to Health Care Implications}

\author{
M. Wong ${ }^{1}$, P.H. Chau ${ }^{2}$, W. Goggins ${ }^{3}$ and J. Woo ${ }^{1}$ \\ 1'Department of Medicine and Therapeutics, Faculty of Medicine, The Chinese University of Hong Kong, Hong Kong SAR. \\ ${ }^{2}$ Faculty of Social Sciences, The University of Hong Kong, Hong Kong SAR. ${ }^{3}$ Division of Biostatistics, School of Public \\ Health, The Chinese University of Hong Kong, Hong Kong SAR. Email: moseswong@cuhk.edu.hk
}

\begin{abstract}
Introduction: Levels of utilization of health services vary socially and geographically. Differences in the rates of usage are also associated with geographical aspects of health care systems. The purpose of this study was to capture spatial variations in hospital health services utilization in the elderly population in Hong Kong, a Special Administrative Region of China.

Materials and Methods: We carried out a secondary analysis of a database from the Hospital Authority (HA) which covers 98\% $(\mathrm{N}=243,245)$ of the total registered deaths in Hong Kong during 1999 to 2005. Deaths at age 65y and above $(\mathrm{N}=184,671)$ were included in the analysis. Age-sex weighted mean utilization ratio of hospital services was calculated by dividing the age-sex weighted mean usage of a particular service for each district by that for the whole territory. The variation in utilization by the seniors was analyzed in terms of four types of services: length of stay (LOS) in HA hospitals, number of inpatient admissions, number of visits to specialist outpatient department (SOPD), and attendances at accident and emergency department (AED).

Results: Deaths at age $65 \mathrm{y}$ and above contributed to $76 \%$ of the total registered deaths. Each district contributed $1.0 \%$ to $9.1 \%$ of the total number of deaths in Hong Kong. Spatial analysis of the age-sex weighted mean utilization ratio showed significant geographic variation in the use of hospital services: the range of difference in the LOS between the lowest and highest district was $44 \%$, while some differences as high as 33\%, 35\% and 39\% in utilization ratios were observed in relation to number of inpatient admissions, visits to SOPD, and attendances at AED respectively. However, the patterns of these variations were not consistent for the four types of service being analyzed.

Conclusions: Geographic variation in the utilization of hospital health services across the 18 districts in Hong Kong among the elderly population during the last three years before death was demonstrated. However, the patterns of variation were different for the types of services being examined. Further studies using primary data at an individual level are needed to explain the variations. Detailed analysis examining the relationship between service provision, accessibility and health outcomes are also indicated in order to inform the planning of health service delivery.
\end{abstract}

Keywords: geographic variations, healthcare delivery, services utilization, elderly

Health Services Insights 2009:2 1-13

This article is available from http://www.la-press.com.

(c) the authors, licensee Libertas Academica Ltd.

This is an open access article distributed under the terms of the Creative Commons Attribution License (http://www.creativecommons.org/licenses/by/2.0) which permits unrestricted use, distribution and reproduction provided the original work is properly cited. 


\section{Introduction}

Elderly people exhibit greatest need for healthcare and are the most frequent users of healthcare services. ${ }^{1-4}$ In Hong Kong, for instance, nearly $40 \%$ of all public inpatient episodes were used by patients aged $65 \mathrm{y}$ or more in 2001. ${ }^{3}$ In addition to the demographic drivers of health services utilization, it has been pointed out that levels of utilization are far from equal either socially or spatially. ${ }^{5-10}$ Previous research has noted geographic differences in health services usage across diverse health service delivery systems. ${ }^{6-14}$ Even within a population of patients sharing broadly similar aetiological characteristics, the dispersion of these characteristics across space results in marked geographic variations in rates of utilization of services. Although Hong Kong only occupies a comparatively small geographic area, small area variations have been observed in mortality and morbidity. ${ }^{15,16}$ However these were observations made ten to twenty years ago, and did not document service utilization. There have been many rapid changes in the physical, social and economic environment in Hong Kong since that period.

This study examines the pattern(s) of variation in the utilization of various hospital services in the public sector in Hong Kong. Health service delivery in Hong Kong is divided into public and private sectors. Hospital services at secondary and tertiary levels are largely provided by public sector and subsidized by the local government. Hospital Authority (HA) and Department of Health provide medical treatment and rehabilitation services to patients through public hospitals, general outpatient and specialist clinics and outreach services throughout the territory, targeted at serving socially disadvantaged and vulnerable groups. The private sector plays a complementary role by providing only six percent of total hospital care. With respect to curative primary care services, private practitioners of Western medicine account for more than half of the market share. However, people believe that public hospitals provide quality services to citizens at reasonable prices. Due to this inadvertently flawed incentive system, there is an over-reliance on hospitals by which the general public also visits the accident and emergency departments (AED), general outpatient department, and specialist outpatient department (SOPD) in the public sector for primary care services.
Hospital services were examined as they consume a disproportionate amount of expenditure in relation to the number of cases treated among the elderly. Information is particularly needed regarding service utilization among the elderly due to the ageing population in Hong Kong and the likely consequence of greater pressure on health and social services in hospital and community setting. The study tests the hypothesis that there are districtwide variations in hospital services utilization in the period preceding death in the elderly population. These geographic variations may directly affect health, both in terms of morbidity, perceived health and mortality. Furthermore, geographic variations may reflect variations in the supply of healthcare and consequently the level of health of a community. ${ }^{17}$ Documentation of any geographic variations in rates of utilization may inform formulation of a health policy which aims to reduce inequalities in health outcomes.

\section{Data and Methods}

This study utilizes the dataset from a project examining the utilization of hospital services in the last three years of life for all age groups in hospitals under the HA from 1st January 1999 to 31 st December 2005. The study had received approval from the Clinical Research Ethics Committee of the Chinese University of Hong Kong. About 98\% of the total registered deaths in Hong Kong occurred in HA hospitals. Since the HA hospitals provide more than $94 \%$ of hospital admission for the major causes of death in Hong Kong, the hospital services used outside the HA are unlikely to influence the estimation significantly. Hospital records had been computerized systematically throughout the public hospitals under HA by an in-house software-The Clinical Management System (CMS) since 1996. The study period was set from 1999, three years after computerization, because previous studies of health services usage conducted in Europe and North America have revealed that the largest proportion of hospital services was consumed during the last 1-3 years of life. ${ }^{18-26}$ The HA database with high coverage percentage would include the majority of death and the information on the utilization of hospital health services of the decedents during their last years of life. 
Deaths records with either missing exact date of death, demographic information (age and sex), or geographical reference to the place of residence of the decedent were excluded from the study population. The exclusion of cases without clear age and sex information was necessary because the proportion of deaths by age and sex would be used to produce age-sex specific weight for the calculation of an age-sex weighted mean utilization ratio. Excluding cases without geographical reference would also reduce systematic bias in geographic comparison of utilization ratio parameter.

Decedents aged 65y or more dying in HA hospitals were analyzed for their service utilization patterns. For reasons of confidentiality, names and addresses were replaced by a patient identifier and the HA district of residence of the decedents. Hospital services used within the HA system during the last three years of life by each patient were matched correspondingly for each individual. Information about gender, date of birth, date of death, each date of admission and discharge, diagnosis for admission, number of HA specialist outpatient episodes and causes of death were traced during this period from the CMS database.

Due to health and social heterogeneity amongst the elderly in terms of age and sex, the study population was divided into three age groups (aged $65 y-74 y, 75 y-84 y$, and $85 y$ or more) and both sexes to provide age-sex specific weights for analysis. These weights were applied for each district to estimate the mean days of length of stay (LOS), number of inpatient admissions, number of visits to SOPD, and attendances to AED during the last three years of life.

The spatial unit of study is based on the 18 administrative districts in Hong Kong. Each of these districts is represented by a District Board and a district management committee which has been established in Hong Kong since 1982 under the District Administration Scheme. ${ }^{27}$ For the purpose of effective coordination and responsiveness of government policies on district needs and problems, district offices communicate and advise the government on issues concerning local well-being such as the provision of services and facilities, the promotion of community, recreational and cultural activities, and environmental improvements within the districts. In addition, the boundaries of the
18 districts have also been constructed to delineate relatively homogeneous spatial units which may be distinguished by demographic profile, socio-economic indicators as well as provision of healthcare services across these districts. ${ }^{3,28}$

A geographical approach was used to show the extent to which the mean utilization of various health services of a district departed from the average of Hong Kong by applying the concept of an analytical spatial measure: the weighted location quotient. Age-sex weighted mean utilization ratio $(\times 100)$ of hospital services was calculated by dividing the agesex weighted mean usage of a particular service for each district by that for the whole territory. In order to test the statistical significance, the $95 \%$ confidence interval (CI) was derived by adopting the Delta method for variance approximation and calculation of CI. ${ }^{29}$ The interpretation of this utilization ratio is similar to that of a standardized mortality ratio, which is computed by dividing the observed deaths by the expected deaths in order to compare the mortality experience of a study population with that of the standard population. Amean service utilization ratio over 100 would indicate a relative concentration of usage in that particular area in comparison to the average of Hong Kong. A ratio less than 100 would indicate that an area has less than the average territory-wide share of the activity. A ratio of 100 would indicate that usage was exactly the same as the mean territory-wide usage.

To quantify the relationship between the district level characteristics and the utilization of inpatient, SOPD and AED services, multilevel Poisson regression models were used. ${ }^{30}$ To proxy the district level demographic and resources for healthcare services provision, four indicators were selected, including (i) education level (proportion of non-student population aged $20 \mathrm{y}$ or above having attained tertiary education), (ii) income level (median household income), (iii) availability of medical staff (number of medical staff in HA hospitals per 1000 population) and (iv) availability of public hospital beds (number of HA hospital beds per 1000 population). These four indicators were used as district level covariates, whereas gender and age at death were used as individual level covariates.

Data analysis was carried out using the statistical package SAS, Release 9.1 (SAS Institute, Inc., Cary, US-NC) and Excel 2003 Version 11 
(Microsoft Corporation, Redmond, US-WA). Map production was performed using ArcMap, Version 9.2 (ESRI, Redlands, US-CA).

\section{Results}

A total of 243,245 deaths were registered in the HA database, which covered $98 \%$ of the total number of deaths registered in Hong Kong during 1999 to 2005. The number (proportion) of deaths excluded from the study for having no reference to details regarding the exact date of death and the age-sex information was 2,507 (1.0\%) and 1,408 (0.6\%) respectively. Further exclusion aiming at minimizing systematic bias from unknown geographical reference to the place of residence of the decedent accounted for a further removal of 2,230 deaths $(0.9 \%)$. A total of 6,145 subjects $(2.5 \%)$ were excluded from the study, whilst the remaining $97.5 \%$ of subjects were further sub-divided into two broad age groups: deaths at age below $65 \mathrm{y}$ accounted for $21.6 \%(\mathrm{~N}=52,429)$ of the original total, and 184,671 subjects $(75.9 \%)$ at age $65 \mathrm{y}$ or more. The latter group constituted the study population.

The demographic and geographic information of the decedents is described in Table 1 . The majority of the elderly died atages between $75 y$ and $84 y(41.3 \%)$, while the young-old (aged 65y-74y) and the old-old (aged $85 \mathrm{y}$ and more) accounted for a smaller but comparable proportion $(29.6 \%$ and $29.0 \%$ respectively). There were more male deaths $(52.7 \%)$ than that of female $(47.3 \%)$. District-wise, the distribution of deaths in the dataset demonstrated substantial geographic difference across the 18 administrative districts, from one with the lowest proportion of death, i.e. Islands $(1.0 \%)$, to another with the highest i.e. Kwun Tong $(9.1 \%)$. This geographical distribution of deaths corresponded to the distribution of elderly population living in the 18 districts with the lowest and highest proportion of elderly population living in Islands and Kwun Tong district respectively.

Hospital services utilization was analyzed in terms of mean days of LOS in hospitals (Table 2; Fig. 1), number of inpatient admissions (Table 2; Fig. 2), number of visits to SOPD (Table 2; Fig. 3) and attendances to AED (Table 2; Fig. 4). The age-sex weighted mean utilization ratio for each of these services across districts varied substantially. Comparing to the average utilization level, the LOS was longer among older persons living in districts such as Southern, Central and Western and Tsuen Wan compared with the average by $26.5 \%$ (C.I. $=123.3$, 129.9), $15.1 \% \quad$ (C.I. $=111.6,118.8)$, and $9.1 \%$ $($ C.I. $=106.1,112.1)$. In contrast, LOS in Tuen Mun, Yuen Long and Sham Shui Po were significantly shorter by $17.1 \%$ (C.I. $=80.6,85.3), 14.2 \%$ (C.I. $=83.8$, $87.7)$ and $11.1 \%$ (C.I. $=87.1,90.8)$. The inter-district difference in utilization ratios between the highest and lowest usage areas was nearly $44 \%$.

For the number of inpatient admissions three years before death, the highest service utilization was observed for Southern, Tai Po and Eastern district. The number of admissions to hospitals was of $20.6 \%$ $($ C.I. $=118.4,122.9), 16.4 \%$ (C.I. $=113.9,118.9)$, and $8.3 \%$ (C.I. $=106.8,109.8)$ higher than the average in Hong Kong. Elderly living in districts such as Sham Shui Po, Wan Chai and Yau Tsim Mong were admitted $12.1 \%$ (C.I. $=86.7,89.1), 10.1 \%$ (C.I. $=86.8,91.4)$, $6.6 \%$ (C.I. $=91.7,95.1)$ less than the local average respectively. The range of difference in terms of the number of inpatient admission episodes was approximately $33 \%$.

As for the number of visits to SOPD, utilization was the highest in Eastern (117.8, C.I. $=116.2,119.4)$, Southern $(110.1$, C.I. $=107.8,112.4)$ and Sha Tin $(105.4$, C.I. $=103.8,107.2)$. The lowest usage ratios were found in Yau Tsim Mong (82.5, C.I. $=80.7$, 84.4), Islands $(87.4$, C.I. $=83.1,91.8)$ and Kowloon City $(92.8$, C.I. $=91.3,94.4)$. The variation in terms of visits to specialist service was about $35 \%$.

The variation in number of attendances at AED revealed a difference as high as 39\%. The highest attendance areas were located in North district (120.8, C.I. $=117.9,123.8)$, Tsuen Wan $(118.2$, C.I. $=115.1$, 121.5) and Tai Po (116.3, C.I. $=113.8,118.8)$, while Central and Western (82.1, C.I. $=80.2,84.1)$, Wong Tai Sin $(82.9$, C.I. $=81.7,84.2)$, and Wan Chai (84.7, C.I. $=82.3,87.2)$ were the areas with the lowest ratios of visit to AED comparing to the local average utilization.

Table 3 showed the ranking of districts in terms of the socio-economic and service provision indicators, as well as the mean utilization ratios. Rankings by education level were consistent with the income level, and rankings by availability of medical staff were consistent with the availability of public hospital beds. However, the rankings by socio-economic 


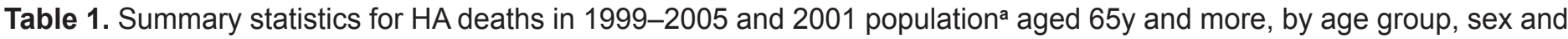
district of residence.

\begin{tabular}{llll}
\hline & HA deaths during 1999-2005 & Proportion & Population $^{\mathbf{a}}$ \\
\hline Age group & & & 458,269 \\
$65-74$ & 54,699 & 29.6 & 227,059 \\
$75-84$ & 76,326 & 41.3 & 61,724 \\
$85+$ & 53,646 & 29.0 & 345,184 \\
Sex & & & 401,868 \\
Male & 97,292 & 52.7 & \\
Female & 87,379 & 47.3 & 28,637 \\
District & & & 74,821 \\
Central and Western & 6,753 & 3.7 & 8,557 \\
Eastern & 16,545 & 9.0 & 50,529 \\
Islands & 1,918 & 1.0 & 55,282 \\
Kowloon City & 14,762 & 8.0 & 81,380 \\
Kwai Tsing & 13,000 & 7.0 & 26,571 \\
Kwun Tong & 16,755 & 9.1 & 24,540 \\
North & 7,035 & 3.8 & 55,390 \\
Sai Kung & 5,353 & 2.9 & 56,310 \\
Sha Tin & 14,843 & 8.0 & 33,970 \\
Sham Shui Po & 11,983 & 6.5 & 35,493 \\
Southern & 8,865 & 4.8 & 26,882 \\
TaiPo & 7,136 & 3.9 & 33,537 \\
Tsuen Wan & 7,756 & 4.2 & 21,487 \\
Tuen Mun & 9,176 & 5.0 & 69,615 \\
Wan Chai & 5,765 & 3.1 & 36,525 \\
Wong Tai Sin & 15,040 & 8.1 & 37,526 \\
Yau Tsim Mong & 10,130 & 5.5 & 6.4 \\
Yuen Long & 11,854 & & \\
\hline
\end{tabular}

a2001 Population Census, Census and Statistics Department, The government of the Hong Kong SAR.

status and by service provision did not show obvious correlation. The rankings in the four mean utilization ratios were also inconsistent.

Results of multilevel models showed that increased inpatient admission was associated with advance age of an individual $(\mathrm{p}<0.0001)$ and higher median household income of the district $(p=0.006)$, whereas decreased inpatient admission was associated with increased education level within the district $(p=0.036)$. Similarly, increased SOPD attendance was associated with being female $(\mathrm{p}<0.0001)$ and higher median household income of the district $(p=0.014)$, whereas decreased SOPD attendance was associated with advance age of an individual $(\mathrm{p}<0.0001)$ and increased education level within the district $(p=0.025)$. As for AED attendance, only advance age $(\mathrm{p}<0.0001)$ and being female $(p<0.0001)$ were associated with increased usage. It was consistent that availability of resources was not associated with usage, while district level socio-economic status was associated with SOPD and inpatient services utilization.

Further analysis was performed on whether patients attended SOPD and AED in their district of residence. On average, about $42 \%$ of SOPD attendance and $55 \%$ of AED attendance were sought 


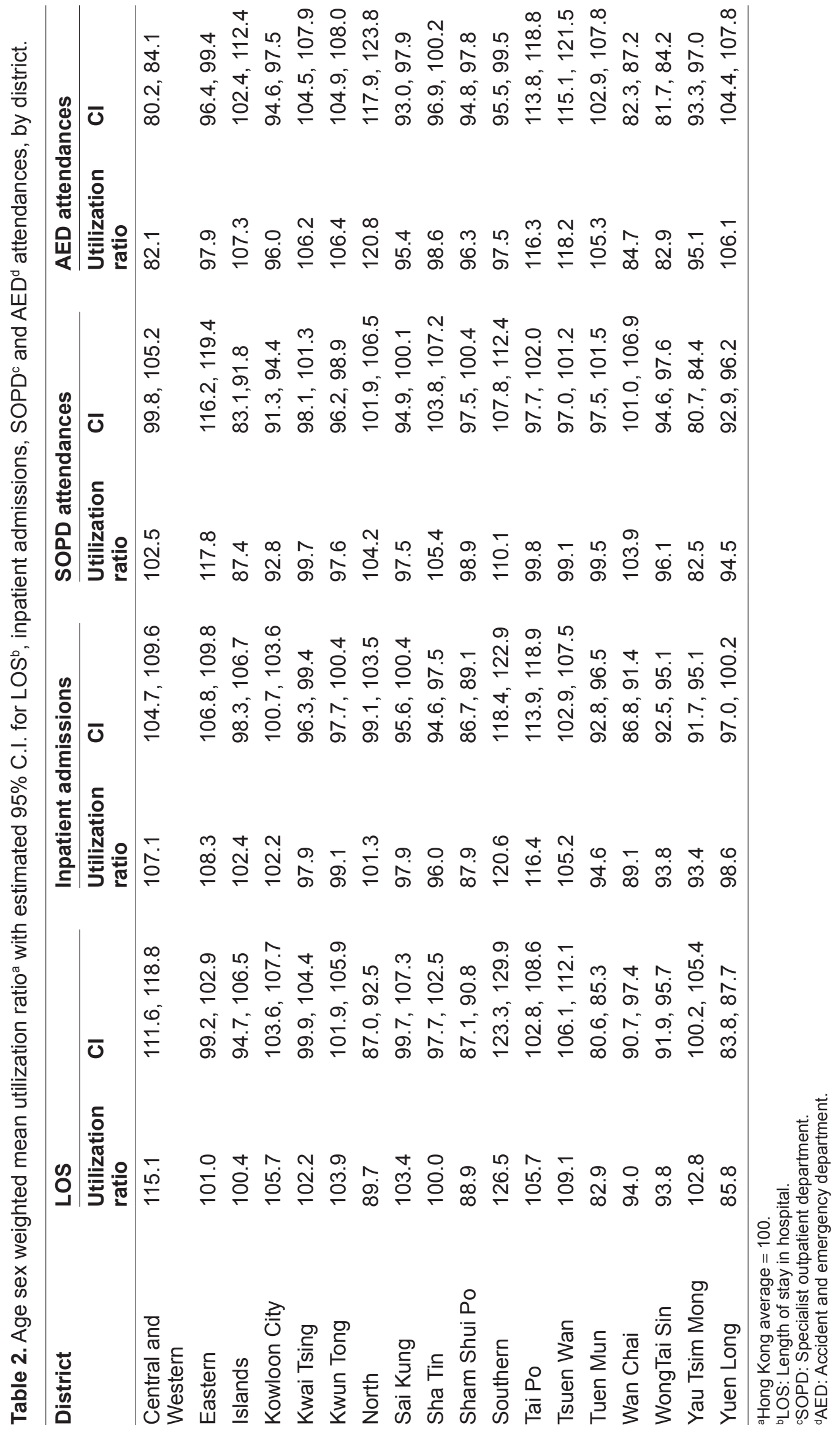




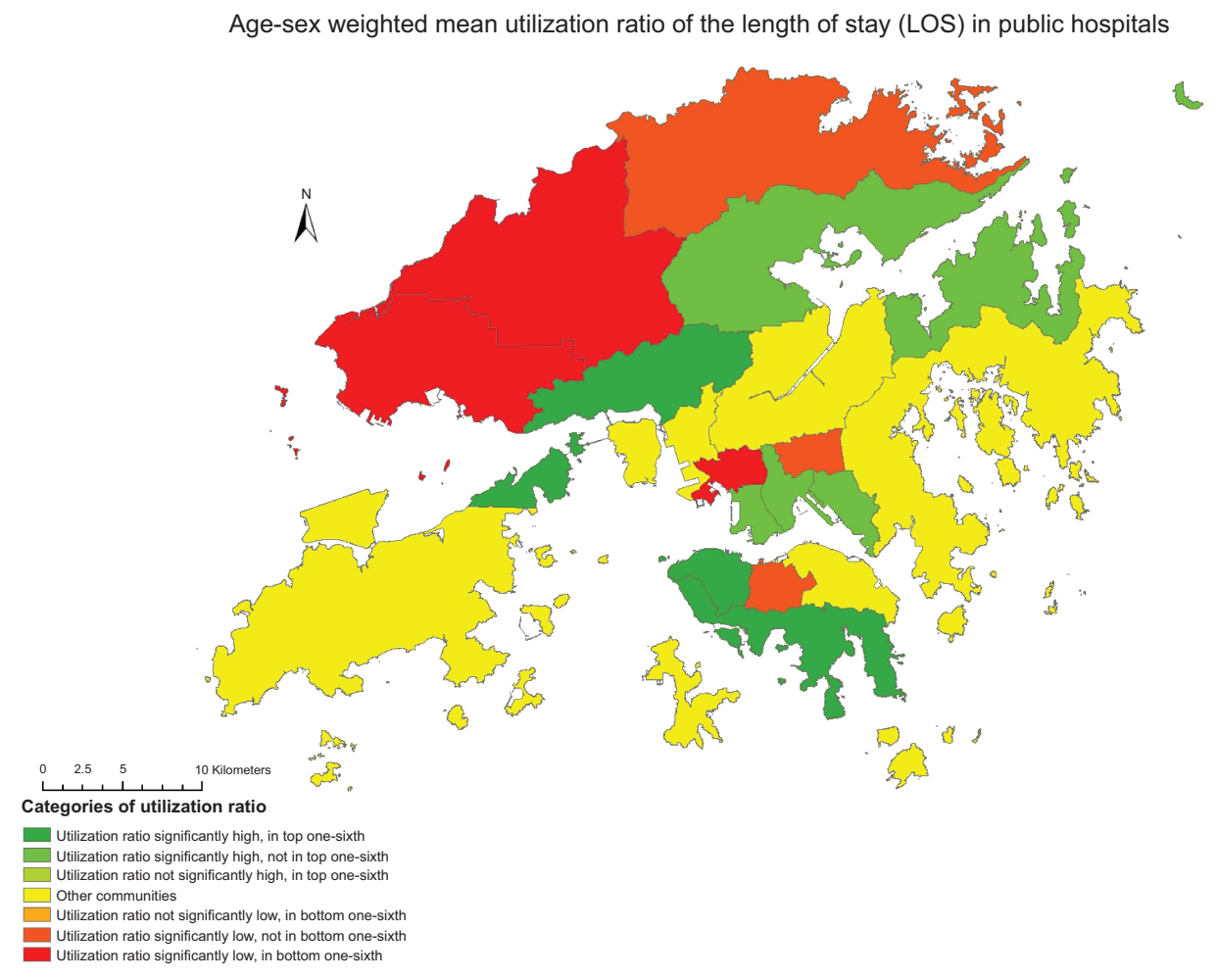

Figure 1. Age-sex weighted utilization ratio for mean LOS by district.

Age-sex weighted mean utilization ratio of the numbers of inpatient admissions to public hospitals

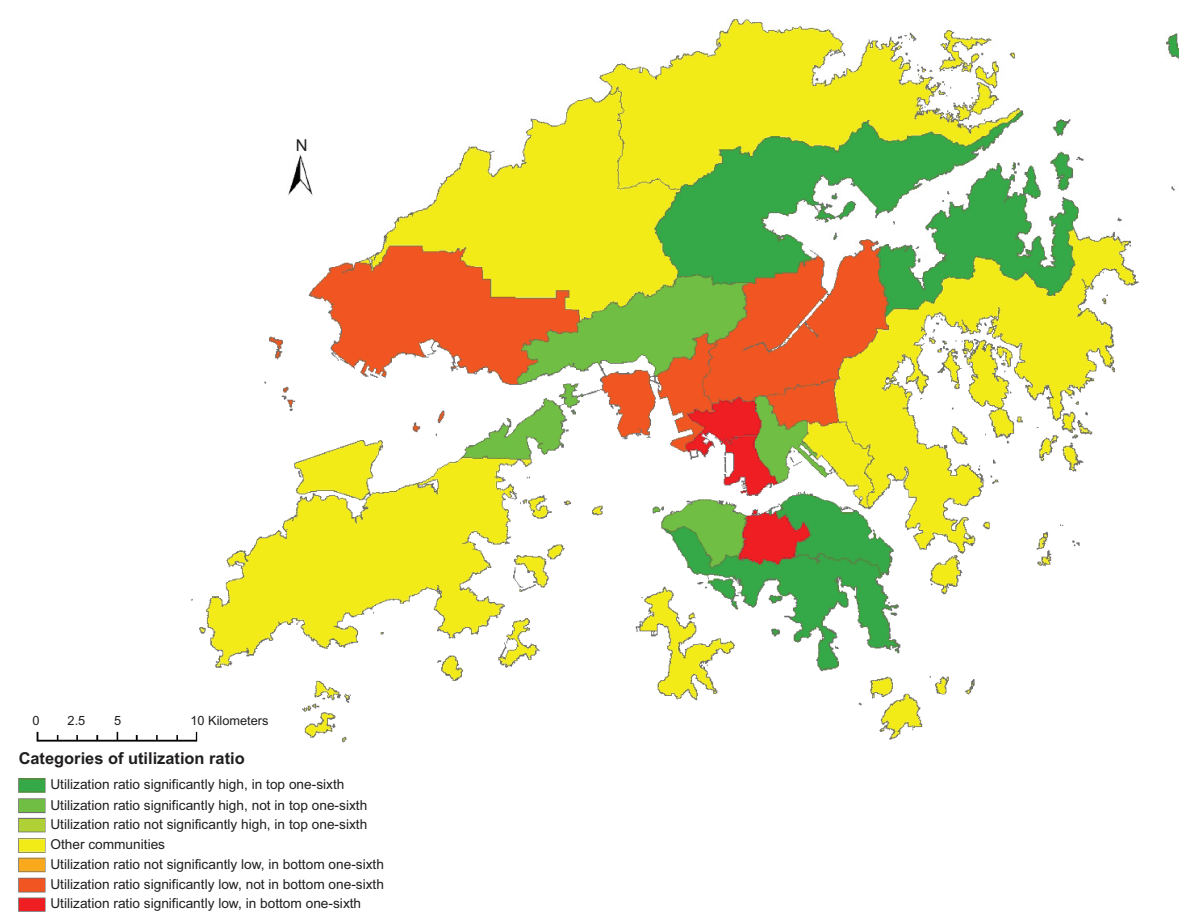

Figure 2. Age-sex weighted utilization ratio for mean number of inpatient admissions by district. 
Age-sex weighted mean utilization ratio of the attendances to specialist outpatient department (SOPD) in public hospitals

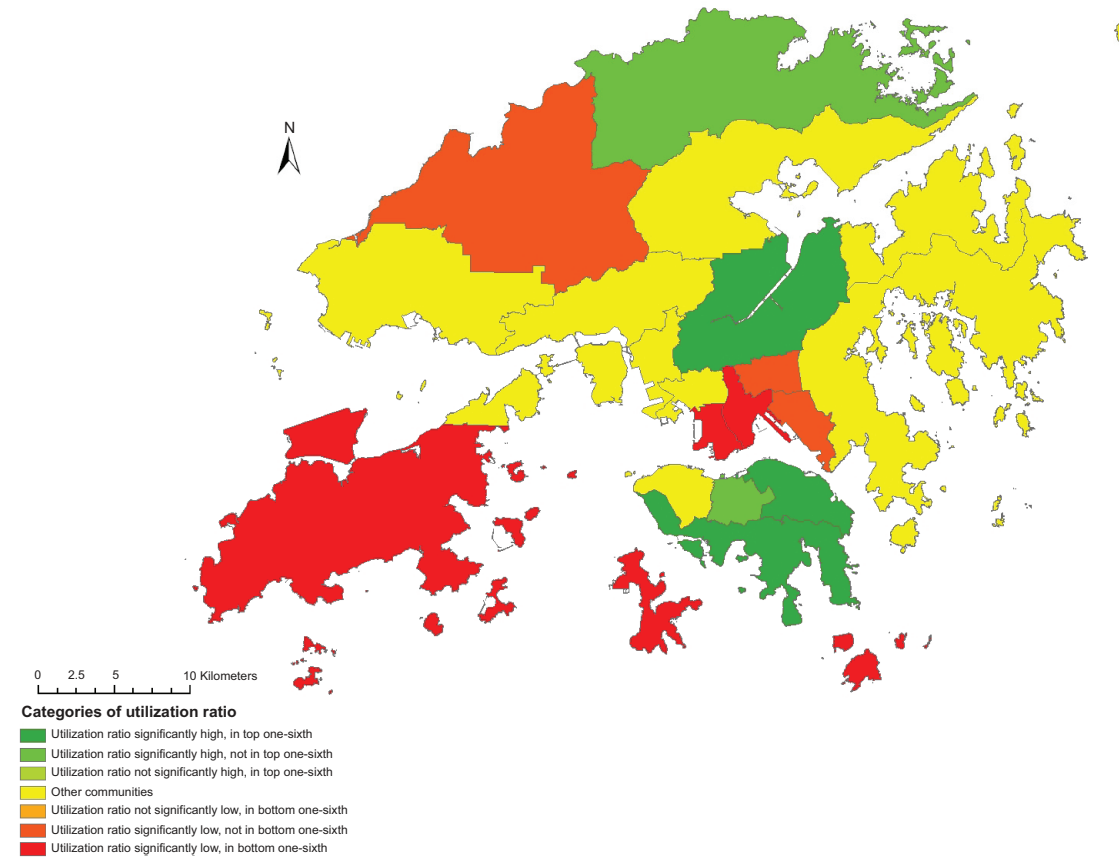

Figure 3. Age-sex weighted utilization ratio for mean number of attendances to SOPD by district.

in the district of residence of the patients. Tuen Mun had the highest proportion of both SOPD attendance $(80 \%)$ and AED attendance $(88 \%)$ in the same district of residence. On the contrary, most residents in Central and Western district had to seek SOPD and AED services outside their district. Findings showed that availability of SOPD and AED services inside the district of residence may or may not related to higher usage (Table 3 ).

The spatial variability of various hospital services utilization ratios, estimated with a 95\% C.I. suggests an existence of substantial district-wide differences in terms of hospital services usage among the older people. Across the different types of services being analyzed, utilizations of hospital services in some areas were about 20\% more than the local mean, while utilizations in some areas were as low as $20 \%$ below the average, representing a difference as high as $40 \%$. Moreover, for different types of services being examined, it is found that the patterns of spatial variation were inconsistent. No district appeared to have a consistent pattern of high or low utilization in all hospital services, although the Southern district was observed to have the highest level of hospitalization service and attendance at SOPD. Socio-economic status, but not availability of resources, at district level may explain some of the differences.

\section{Discussion}

This study provides new data regarding small area variations in use of health services in Hong Kong that had not been studied in detail before, although variations in mortality and morbidity had been documented between one to two decades ago. Due to the small geographical area, studies on within territory variations had received little interest. The introduction of computerized hospital records in recent years enabled further studies in this area. One of the 'contemporary approaches' of medico-social research involves spatial research into the locational patterning, spatial planning, the utilization of main elements of healthcare delivery system, together with identifying the features of the healthcare facilities that influence their efficiency and effectiveness. ${ }^{31,32}$ By using a classical measurement showing the extent of relative localization of an activity to some norms, the age-sex adjusted mean utilization ratios demonstrate significant differences in public hospital services utilization during the last three years of life among 


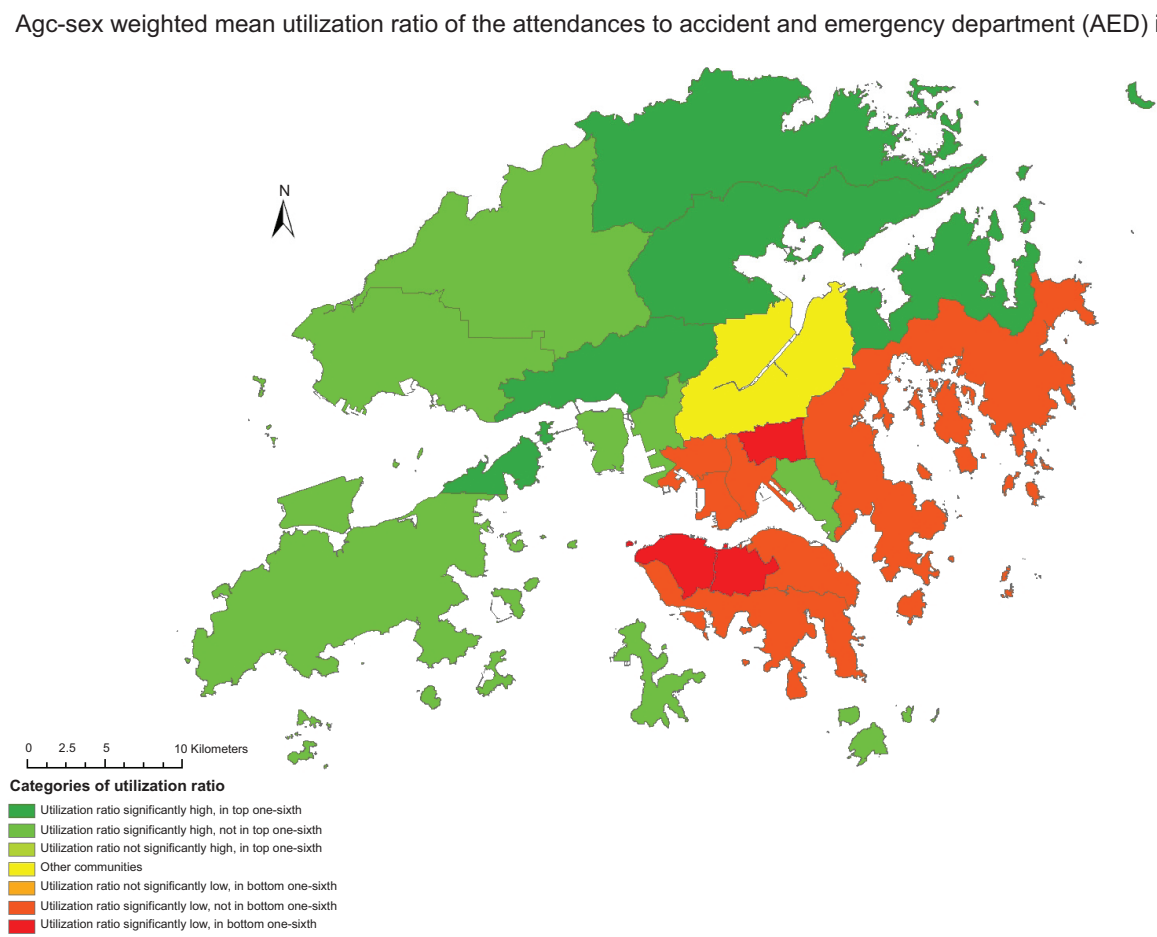

Figure 4. Age-sex weighted utilization ratio for mean number of attendances to AED by district.

the elderly across the 18 administrative districts in Hong Kong. With respect to the LOS in hospitals, most parts of the Hong Kong Island (Central and Western, and Southern districts) were found to have longer duration of stay by $27 \%$ compared with the average length, while the northwestern parts of the New Territories (Yuen Long, Tuen Mun districts) and locality such as Sham Shui Po were areas where the shortest durations of stay in hospital was found. The number of inpatient admissions followed a different pattern compared with that of the LOS. Districts with the highest admission to hospitals were found in Hong Kong Island (Southern and Eastern district) and Tai Po, while the lowest admission was found in old urban core districts, such as Sham Shui Po, Wan Chai and Yau Tsim Mong. Possible explanations for these different patterns of hospitalization service include variation in causes for admission requiring varying duration of stay in hospitals, or differences in resource availability and clinical efficiency in that different hospitals have different management patterns for admissions and discharges. Some normative studies have also indicated that the use of hospitals varies according to a number of factors specific to institutions, such as amount and volume of service provided, the character of the service area and relative location of the hospital, service quality, age and reputation of the hospital. $8,9,33$ Some other crucial factors governing utilization appeared to be socio-geographic such as distance, race, culture, and income., ${ }^{9,34-37}$

Hospitals provide locations for major inpatient treatment of acute and chronic conditions. In the absence of a structured primary care system, hospitals also provide primary types of contact, in the outpatient and emergency services. The attendance at SOPD showed that Eastern, Southern and Sha Tin districts were the areas with the highest usage. On the contrary, the elderly living in Yau Tsim Mong, Islands and Kowloon City districts used the least service. Usage variation in outpatient services could possibly be attributed to the varying level of comorbid chronic conditions in the elderly across districts, reflecting different overall morbidity burden. Another possibility is the availability of healthcare resources in terms of staff and overall health budget may vary between districts. ${ }^{38}$ It is possible that varying attendance to outpatient service is due to the varying level of service provision. 


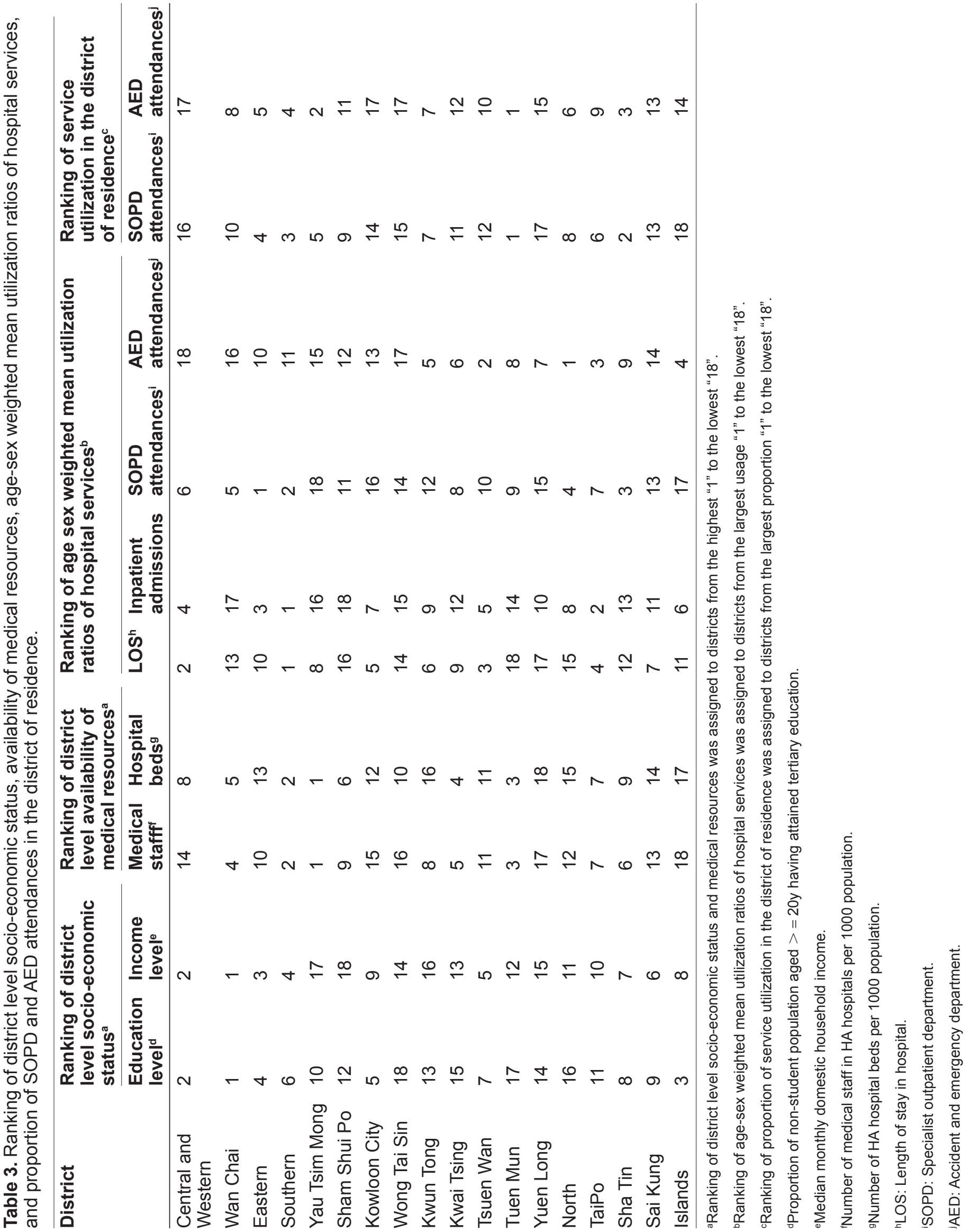


With respect to visits to AED, elderly living in North, Tai Po and Tsuen Wan districts used this service the most, while the lowest users were found in areas such as Central and Western, and Wan Chai on the Hong Kong Islands, as well as an old district, Wong Tai Sin, on the Kowloon side. Regional variation in rates of AED visits is unlikely to be attributable to affordability, since the fee for AED attendance is low and may be waived for those who cannot afford to pay. AED may be used as a primary care facility as it is open 24 hours a day, and up to one third of the attendances may not be classified as emergencies. It has been shown that up to two thirds of attendances to AED and nearly half of the visits to SOPD could have been better managed in the community with an adequate primary care.$^{39}$ High usage in one area may indicate lack of other primary care services or lower rates of private general practitioner consultations as a result of poor affordability.

Results of the multilevel modelling demonstrated that socio-economic indicators at district level could predict the hospital services utilization at individual level. Increasing age is significantly related to increasing hospital admissions and attendances at AED, but decreasing SOPD attendance. It has been noted that advancing age is exponentially related to decreasing physical competence ${ }^{1}$ and increased (co)morbidity, ${ }^{4,40}$ which required more frequent hospitalization $^{2,3}$ as well as primary healthcare contacts for acute conditions. ${ }^{4}$ With readily accessible and affordable AED services, older people may tend to visit AED for primary and emergency healthcare rather than spending longer waiting time for medical consultation and follow-up at SOPD. It was also noted that females used more SOPD and AED services than males. This might be explained by the higher morbidity among women than men, ${ }^{2,41}$ such that women had more frequent visits to SOPD and AED to deal with their health problems.

In our study, availability of hospital service resources at district level was not associated with the individual level usage. Apart from the allocation of healthcare resources to any given location, the way these services are provided by the system and the health seeking behaviors of the patients could also affect the utilization pattern. ${ }^{31,32}$ For a territory occupying a small geographical area such as Hong Kong, the districts are in close proximity to each other, and the population mobility is further enhanced by an extensive and efficient public transport network. Although the healthcare resources allocation varied geographically, patients might access freely and easily to their preferred locations where they received services. Hence, the spatial variation in availability of healthcare resources in a district may not determine the usage of health services at individual level. This implies that a variety of non-spatial factors may interact with the services provision, which in turn affect actual access and usage by an individual. With respect to the socio-economic status of a district in association with SOPD and AED usage, the education and income indicators were highly correlated to each other. The interpretation of the signs of their fitted coefficients may be affected. Therefore, further analysis is suggested in order to explore the underlying association between socio-economic indicators and hospital services utilization.

\section{Limitations}

Although the coverage of service utilization data in this study not $100 \%, 98 \%$ of the total registered death in Hong Kong was reflected in this HA database, so that the dataset may be considered representative as indicative of the major pattern of hospital services utilization. Methodologically, examining geographical variation at a finer level within each district was not possible due to the limitation of data aggregation in terms of place of residence of the decedents, and small-area problem might have arisen in locations where deaths counts were too small. In addition, sociodemographic information and morbidity conditions of the individuals were not included in our dataset. Therefore, this secondary data analysis of the spatial variation concerning service usage alone may only have limited public health significance.

\section{Conclusion}

We have established that there is geographic variation in the utilization of hospital health services across the 18 districts in Hong Kong among the elderly population during the last three years before death. However, the patterns of variation were different depending on the types of services being examined. Further studies using primary data at an individual level are needed to explain the variations. Detailed analysis into the relationship between service 
provision, accessibility and health outcomes are also indicated in order to inform the planning of health service delivery. ${ }^{15,42}$

\section{Acknowledgement}

The authors would like to acknowledge the Hospital Authority for the provision of recent data on public hospital services utilization. This study is partially supported by the Health and Health Services Research Fund of the HKSAR government as well as the 'CADENZA: A Jockey Club Initiative for Seniors' project funded by The Hong Kong Jockey Club Charities Trust.

\section{Disclosures}

\section{The authors report no conflicts of interest.}

\section{References}

1. Birdsall SS. Planning urban service locations for the elderly. In: Golant SM, editor. Location and environment of elderly population. New York: Wiley Halsted Press; 1979.

2. Anderson OW, Anderson R. Patterns of use of health services. In: Freeman H, Levine S, Reeder L, editors. Handbook of medical sociology, 2nd ed. Englewood Cliff, New Jersey: Prentice-Hall; 1972.

3. Hospital Authority. Statistical Report 2001/2002 [Online] 2003 [cited 2009 Jun 10]; Available from: URL: http://www.ha.org.hk/haho/ho/hesd/ 123229e.pdf

4. Rennemark M, Holst G, Fagerstrom C, Halling A. Factors related to frequent usage of the primary healthcare services in old age: findings from The Swedish National Study on Ageing and Care. Health Soc Care Comm. 2009;17(3):304-11.

5. Joseph AE, Phillips DR. Accessibility and Utilization: Geographical Perspectives on Health care Delivery. London: Harper and Row Ltd: 1984.

6. Virnig BA. Toward a better understanding of the role of geography in intensity of end-of-life care. Must we first come to an understanding of endof-life care? Med Care. 2007:45(5):374-6.

7. Maheswaran R. Supply of inpatient services for elderly people and geographical variation in medical admissions in a health district in England. Public Health. 1997;111:411-5.

8. Wennberg JE, Fisher ES, Stukel TA, Skinner JS, Sharp SM, Bronner KK. Use of hospitals, physician visit, and hospice care during the last six months of life among cohorts loyal to highly respected hospitals in the United States. BMJ. 2004;328:607-11.

9. Busato A, Kunzi B. Primary care supply and other key determinants of health care utilization: the case of Switzerland. BMC Health Serv Res. 2008;8:8.

10. Westert GP, Groenewegen PP, Boshuizen HC, Spreeuwenberg PMM, Steultjens MPM. Medical practice variations in hospital care; time trends of a spatial phenomenon. Health Place. 2004;10:215-20.

11. Thomas C, Kelman HR. Health services use among the elderly under alternative health service delivery systems. J Community Health. 1990;15:77-92.

12. Kelman HR, Thomas C. Hospital and ambulatory service use by the urban elderly under different health care delivery systems. Med Care. 1988;26:739-47.

13. Mutran E, Ferraro KF. Medical need and use of services among elder men and women. J Gerontol. 1988;43:S162-71.

14. Evashwick $\mathrm{C}$, et al. Factors explaining the use of health care services by the elderly. Health Serv Res. 1984;19:357-82.
15. Wong CM, Hedley AJ, Lam TH, Bacon-Shone J, Ma S, Fung H, et al Estimation and variations in health care needs between small areas in Hong Kong using routine statistics on morbidity, mortality and socioeconomic and demographic characteristics of the population HSRC Report \# 621009 Dec 1999.

16. Lloyd OL, Wong TW, Wong SL, Yu TSI. Atlas of disease mortalities in Hong Kong for the three five-year periods in 1979-93. Hong Kong: The Chinese University Press; 1996.

17. Fein R. On achieving access and equity in health care. Milbank $Q$. 1972:50:157-90.

18. Galvin ME, Fan M. The utilization of physicians' services in Los Angeles County. J Health Soc Behav. 1975;16:74-94.

19. Haynes RM, Bentham CG. The effect of accessibility on general practitioner consultations, out-patient attendances and in-patient admissions in Norfolk, England. Soc Sci Med. 1982;16:561-9.

20. Himsworth RL, Goldacre MJ. Does time spent in hospital in the final 15 years of life increase with age at death? A population based study. BMJ. 1999;319:1338-9.

21. Busse R, Krauth C, Schwartz FW. Use of acute hospital beds does not increase as the population ages: results from a seven year cohort study in Germany. J Epidemiol Community Health. 2002;56:289-93.

22. Dixon T, Shaw M, Frankel S, Ebrahim S. Hospital admissions, age, and death; retrospective cohort study. BMJ. 2004;328:1288-90.

23. Temkin-Greener H, Meiners MR, Pretty E, et al. Spending-down to Medicaid in the nursing home and in the community. A longitudinal study from Monroe County, New York. Med Care. 1993;31:663-79.

24. Mukamel DB, Chou C, Zimmer JG, et al. The effect of accurate patient screening on the cost effectiveness of case management programme. Gerontologist. 1997;37:777-84.

25. Scitovsky AA. The high cost of dying: What do the data show? Milbank $Q$. 1984;62:591-607.

26. Scitovsky AA. "The high cost of dying" revisited. Milbank $Q$. 1994;72:561-91.

27. Home Affairs Department. Hong Kong the facts: District Administration. [Online] 2008 Jan [cited 2009 Jun 10]; Available from: URL:http://www. had.gov.hk

28. Census and Statistics Department. 2006 Population By-census: Basic tables for district council districts. [Online] 2007 May 31 [cited 2009 Jun 10]; Available from: URL:http://www.bycensus2006.gov.hk/FileManager/EN/ Content_962/06bc_dcd.pdf

29. Beyene J, Moineddin R. Methods for confidence interval estimation of a ratio parameter with application to location quotients. BMC Med Res Methodol. 2005;5:32.

30. Goldstein H. Multilevel Statistical Models. 3rd ed. London: Edward Arnold; 2003.

31. Giggs JA. Human health problems in urban areas. In: Herbert DT, Smith DM, editors. Social problems and the city. Oxford: Oxford University Press; 1979.

32. Phillips DR. Contemporary issues in the geography of health care. Norwich: Geo Books; 1981.

33. Bailey W, Phillips DR. Spatial patterns of use of health services in the Kingston Metropolitan Area, Jamaica. Soc Sci Med. 1990;30:1-12.

34. Powell M. On the outside looking in: Medical geography, medical geographers and access to health care. Health Place. 1995;1:41-50.

35. Lieu TA, Newacheck PW, McManus MA. Race, ethnicity, and access to ambulatory care among US adolescents. Am J Public Health. 1993;83(7):960-5.

36. Gellet GA, Maxwell RM, Higgins KV, Mai KK, Lowery R. Barriers to health care access and utilization among Vietnamese Americans in southern California. Health Place. 1995;1:91-9.

37. Feinson MC, Popper M. Does affordability affect mental health utilization? A United States-Israel comparison of older adults. Soc Sci Med. 1995;40:669-78.

38. Hospital Authority. HA Statistical Report. [Online] 2007 [cited 2009 Jun 10]; Available from: URL: http://www.ha.org.hk/ 
39. Harvard University Consultancy Team. Improving Hong Kong's health care system: Why and for whom? [Online] 1999 Apr 12 [cited 2009 Jun 10]; Available from: URL:http://www.fhb.gov.hk/en/press_and_publications/ consultation/HCS.HTM\#MAIN\%20REPORT

40. Starfield B, Lemke KW, Herbert R, Pavlovich WD, Anderson G. Comorbidity and the use of primary care and specialist care in the elderly. Ann Fam Med. 2005;3:215-22.
41. Clearly PD, Mechanic D, Greenley JR. Sex differences in medical care utilization: an empirical investigation. $J$ Health Soc Behav. 1982;23:106-19.

42. Gibson A, Asthama S, Brigham P, Moon G, Dicker J. Geographies of need and the new NHS: methodological issues in the definition and measurement of the health needs of local populations. Health Place. 2002;8;47-60.

\section{Publish with Libertas Academica and every scientist working in your field can read your article}

"I would like to say that this is the most author-friendly editing process I have experienced in over 150 publications. Thank you most sincerely."

"The communication between your staff and me has been terrific. Whenever progress is made with the manuscript, I receive notice. Quite honestly, l've never had such complete communication with a

$$
\text { journal." }
$$

" $L A$ is different, and hopefully represents a kind of scientific publication machinery that removes the hurdles from free flow of scientific thought."

Your paper will be:

- Available to your entire community free of charge

- $\quad$ Fairly and quickly peer reviewed

- Yours! You retain copyright

http://www.la-press.com 